\title{
Spatially Resolved Molecular Compositions of Insoluble Multilayer Deposits Responsible for Increased Pollution from Internal Combustion Engines
}

Max K. Edney, Joseph S. Lamb, Matteo Spanu, Emily F. Smith, Elisabeth Steer, Edward Wilmot, Jacqueline Reid, Jim Barker, Morgan R. Alexander, Colin E. Snape, and David J. Scurr*

Cite This: ACS Appl. Mater. Interfaces 2020, 12, 51026-51035

Read Online

ABSTRACT: Internal combustion engines are used heavily in diverse applications worldwide. Achieving the most efficient operation is key to improving air quality as society moves to a decarbonized energy system. Insoluble deposits that form within internal combustion engine components including fuel injectors and filters negatively impact $\mathrm{CO}_{2}$ and pollutant emissions. Understanding the composition, origins, and formation mechanisms of these complex materials will be key to their mitigation however, previous attempts only afforded nondiagnostic chemical assignments and limited knowledge toward this. Here, we uncover the identity and spatial distribution of molecular species from a gasoline direct injector, diesel injector, and filter deposit in situ using a new hyphenation of secondary ion mass spectrometry and
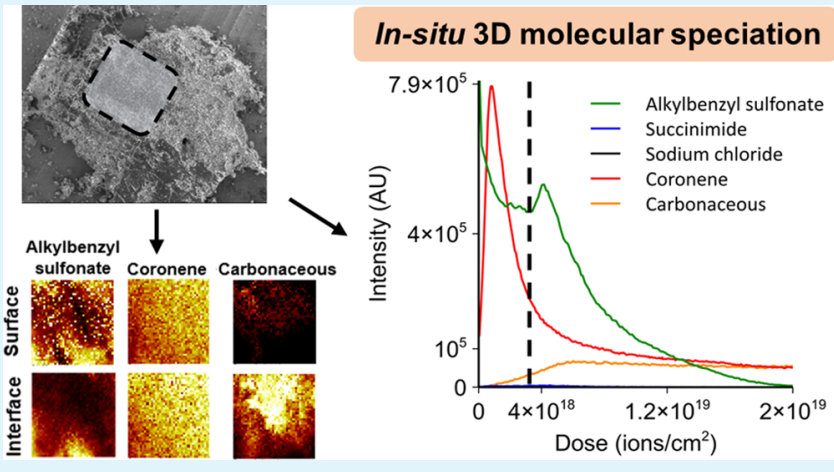
the state-of-the-art Orbitrap mass analyzer (3D OrbiSIMS) and elemental analysis. Through a high mass resolving power and tandem MS we unambiguously uncovered the identity, distribution, and origin of species including alkylbenzyl sulfonates and provide evidence of deposit formation mechanisms including formation of longer chain sulfonates at the gasoline deposit's surface as well as aromatization to form polycyclic aromatic hydrocarbons up to $\mathrm{C}_{66} \mathrm{H}_{20}$, which were prevalent in the lower depth of this deposit. Inorganic salts contributed significantly to the diesel injector deposit throughout its depth, suggesting contamination over multiple fueling cycles. Findings will enable several strategies to mitigate these insoluble materials such as implementing stricter worldwide fuel specifications, modifying additives with adverse reactivity, and synthesizing new fuel additives to solubilize deposits in the engine, thereby leading to less polluting vehicles.

KEYWORDS: 3D OrbiSIMS, internal combustion engine, fuel deposits, gasoline direct injection, diesel

\section{INTRODUCTION}

It is proposed that by $2040,70 \%$ of light passenger vehicles will still use internal combustion engines. ${ }^{1,2}$ These offer benefits such as efficiency, cost, reliability, and flexibility of burning new generation fuels and as such will feature heavily in the future global vehicle mix for road, rail, off-road, and marine applications. $^{3-8}$ Two processes in internal combustion engines that greatly influence emissions and efficiency are fuel injection, where fuel is injected into the combustion chamber, and fuel filtration, where fuel is repeatedly passed through and cleaned for recirculation back into the fuel injectors. However, insoluble deposits, caused by contaminated or unstable fuel mixtures, ${ }^{9,10}$ commonly afflict these components and lead to a decrease in fuel economy and an increase in pollutant emission from internal combustion engines. ${ }^{11-14}$ For example, deposit formation can increase particulate emissions by up to 5 times. ${ }^{13,15}$ The World Health Organization estimates that poor air quality leads to 7 million premature deaths each year; ${ }^{16}$ therefore, mitigating deposits will present benefits from an environmental and healthcare perspective.

A fundamental step in the quest of mitigating deposits is to understand their underlying chemical composition and origins. A review by Edney et al. summarizes the key analysis techniques applied to date. ${ }^{17}$ Scanning electron microscopy (SEM) offers semiquantitative elemental analysis and facile sample preparation and has identified contributing elements including sulfur, phosphorus, and calcium. This has implicated possible origins from fuel derived material and lubricating oil. ${ }^{17}$ Infrared spectroscopy allows functional group identification

Received: August 12, 2020

Accepted: October 19, 2020

Published: October 29, 2020 
and has inferred the presence of fuel constituents in the past such as $\mathrm{C}_{16}$ and $\mathrm{C}_{18}$ carboxylic acids and components from additive packages such as "noncommercial" low molecular weight polyisobutylene succinimides. ${ }^{18}$ Carboxylic acids have several potential sources such as biodiese ${ }^{19}$ or corrosion inhibition additive packages that contain sodium and calcium. $^{20}$ X-ray photoelectron spectroscopy (XPS) has provided quantified elemental surface information from deposits previously. ${ }^{21,22}$ Secondary ion mass spectrometry (SIMS) requires no sample preparation for deposit analysis and can probe the provenance of material through ion beam etching. Previous work on internal diesel injector deposits using time-of-flight SIMS with a $\mathrm{Bi}_{3}{ }^{+}$ion beam identified ion fragments such as $\mathrm{C}_{3} \mathrm{~N}^{-}$and $\mathrm{C}_{6}^{-}$, but many were nondiagnostic. $^{23-25}$ This limitation arose due to high fragmentation of analyte and a relatively low mass resolving power of the time-of-flight analyzer.

$3 \mathrm{D}$ OrbiSIMS is a recently developed technique that relies on similar working principles to time-of-flight SIMS. ${ }^{26}$ Here, the Orbitrap analyzer affords greater mass accuracy and a more than 10-fold increase in mass resolving power than the time-offlight analyzer. It also provides the capability for chemical speciation using secondary fragmentation of ions of interest to make unambiguous assignments. ${ }^{26}$ The argon gas cluster ion beam can perform simultaneous sample etching and analysis, maintaining diagnostic chemical species for identification. ${ }^{27}$ This work is the first application of 3D OrbiSIMS to provide spatially resolved information about key molecular species in insoluble deposits. We present 3D OrbiSIMS data from samples sourced from a gasoline and diesel fuel injector and a diesel filter component combined with MS/MS analysis to demonstrate unambiguous identification of deposit components and to showcase the suitability of the technique. This study was limited to analyzing one sample type of each component; however, analytical repeats were taken on each sample. We focus on inorganic salts and molecular species including succinimides that are used in both fuel and engine lubricating oil formulations and alkylbenzyl sulfonates, added directly to lubricating oil additive packages in gasoline and diesel engines. ${ }^{28}$ We also identify large polycyclic aromatic hydrocarbons (PAHs) extending up to $800 \mathrm{Da}$, previously only speculated to be present in deposits. Comparison of the maximum size of PAHs gave insight into how the deposit matrix is formed in the engine components. We performed quantitative elemental surface analysis by XPS to complement the 3D OrbiSIMS data. This is the first comparison of deposits from different engine components across the gasoline and diesel fuel streams. Findings have significant implications for the upward and downward fuel stream as well as engine, fuel injector, and additive manufacturers.

\section{EXPERIMENTAL SECTION}

2.1. Materials. Engine components were retrieved from engines recovered from real-world vehicles in operational service. Injector samples were then disassembled, and samples were analyzed ex situ. The filter sample was cut out from the diesel fuel filter and subsequently vacuum oven-dried at $140{ }^{\circ} \mathrm{C}$ and $0.01 \mathrm{mbar}$ for $8 \mathrm{~h}$ to remove diesel volatiles that could compromise the instrument's vacuum chambers, while retaining the heavier deposit fractions that cause blockage of the filter.

2.2. 3D OrbiSIMS. 3D OrbiSIMS analysis was conducted by using a Hybrid SIMS instrument with the technique outlined by Passarelli et $\mathrm{al}^{26}$ Secondary ions were collected using the Q Exactive HF Orbitrap mass analyzer (affording a mass resolution of 240000 at $\mathrm{m} / \mathrm{z}$
200) that was calibrated using clustered silver cluster ions prior to all sample measurements. In all profiling and imaging experiments, a 20 $\mathrm{keV} \mathrm{Ar}_{3000}{ }^{+}$gas cluster ion beam was used, defocused to $20 \mu \mathrm{m}$ with a cycle time of $200 \mu \mathrm{s}$, an injection time of $500 \mathrm{~ms}$, a duty cycle of $4.4 \%$, and a target current of $0.23 \mathrm{nA}$. Charge compensation was achieved with a low-energy electron flood gun $(21 \mathrm{eV}$ and extraction bias of $-20 \mathrm{~V})$ and by regulation of the main chamber with argon gas $(9 \times$ $10^{-7} \mathrm{mbar}$ ) to delocalize any accumulation of charge surrounding the sample. Deposit sample data were collected over a mass range of $\mathrm{m} / z$ 75-1125 using SurfaceLab software (version 7.1.b (IONTOF $\mathrm{GmbH})$ ), with the application programming interface (API) provided by Thermo Fisher for control of the Orbitrap MS portion of the instrument. Data processing was performed using SurfaceLab Version 7.1.c (ION-TOF GmbH).

Single beam depth profiles using $\mathrm{Ar}_{3000}{ }^{+}$ions from the gas cluster source to produce secondary ions which were analyzed by the Orbitrap analyzer (Mode 4$)^{26}$ were acquired for all deposit samples using one area per polarity. The analysis areas were $300 \times 300 \mu \mathrm{m}^{2}$ (negative polarity) and $400 \times 400 \mu \mathrm{m}^{2}$ (positive polarity) for the gasoline deposit, $200 \times 200 \mu \mathrm{m}^{2}$ for the diesel injector deposit, and $300 \times 300 \mu \mathrm{m}^{2}$ for the diesel filter. In all cases an interlaced border was used to prevent boundary effects. The gasoline deposit profiles were acquired over $128000 \mathrm{~s}$ (negative) and $85000 \mathrm{~s}$ (positive), the diesel injector deposit profiles over $15000 \mathrm{~s}$, and the filter profiles over $170 \mathrm{~s}$. This afforded a total primary ion dose density of $7.98 \times 10^{16}$ ions $/ \mathrm{cm}^{2}$ (positive polarity) and $1.27 \times 10^{17}$ ions $/ \mathrm{cm}^{2}$ (negative polarity) for the gasoline deposit, $2.75 \times 10^{16}$ ions $/ \mathrm{cm}^{2}$ for the diesel injector deposit, and $1.69 \times 10^{14}$ ions $/ \mathrm{cm}^{2}$ for the diesel filter deposit. The sawtooth raster mode was used to acquire positive and negative secondary ion data for the gasoline and filter deposit and positive ion data for the diesel injector deposit. Random raster mode was used to acquire negative ion data from the diesel injector deposit. MS/MS spectra were acquired over $50 \mathrm{~s}$ with an analysis area of $300 \times 300$ $\mu \mathrm{m}^{2}$ in sawtooth raster mode with mass windows of $10 \mathrm{amu}$ and normalized collision energy of $20 \mathrm{eV}$. We performed three analytical repeats for each sample analyzed.

Chemical images were obtained using Mode 7 of the instrument, ${ }^{26}$ where the gas cluster ion beam $\left(\mathrm{Ar}_{3000}{ }^{+}\right)$rasters the sample surface with a low current and obtains secondary ion data at different positions. These were acquired over a total of two scans (900 s total acquisition time) with a resultant pixel size of $5 \mu \mathrm{m}$ and an area of 300 $\times 300 \mu \mathrm{m}^{2}$ with a noninterlaced border. Images were later cropped to $200 \times 200 \mu \mathrm{m}^{2}$, normalized to the total ion image, and scaled to match the intensity of each depth and for both samples. All imaging and profiles were performed with the same settings outlined prior and with a sputtering area of $200 \times 200 \mu \mathrm{m}^{2}$.

2.3. Profilometry. Images of craters on the gasoline and diesel injector deposits were taken using a Zeta $203 \mathrm{D}$ optical profiler with a $20 \times$ optical lens. Zeta 3D software was used for acquisition and interpretation.

2.4. X-ray Photoelectron Spectroscopy. The samples were subjected to XPS analysis using the Kratos AXIS ULTRA DLD liquid phase photoelectron spectrometer (LiPPS) with a monochromated Al $\mathrm{K} \alpha \mathrm{X}$-ray source $(1486.6 \mathrm{eV})$ with a source power of $120 \mathrm{~W}$ for gasoline and diesel injector deposits and $60 \mathrm{~W}$ for the diesel filter deposit. Spectra were acquired with the Kratos VISION II software. A charge neutralizer filament (2.0 A current, $3.6 \mathrm{~V}$ balance, $1.2 \mathrm{~V}$ bias) was used to prevent surface charging. Small spot mode was used by measuring a sample area of approximately $200 \times 200 \mu \mathrm{m}^{2}$. The analysis chamber pressure was better than $5 \times 10^{-9} \mathrm{mbar}$. Gas cluster ion beam etching $\left(20 \mathrm{keV} \mathrm{Ar}_{500}{ }^{+}\right.$cluster beam, etch area of $0.75 \mathrm{~mm}$ for gasoline deposit and $1.2 \mathrm{~mm}$ for diesel injector deposit) was performed on the injector parts prior to analysis to remove surface contamination (470 and $864 \mathrm{~s}$ for the gasoline and diesel injector deposit, respectively), while this was not performed on the filter deposit due to the porous nature of the filter material, which made etching of the sample surface and interpreting depth profiling data unfeasible with the instrument. Low-resolution survey spectra were recorded between a binding energy range 1200 to $-5 \mathrm{eV}$; the pass energy was $160 \mathrm{eV}$ (gasoline and diesel injector deposits) and $80 \mathrm{eV}$ 
a
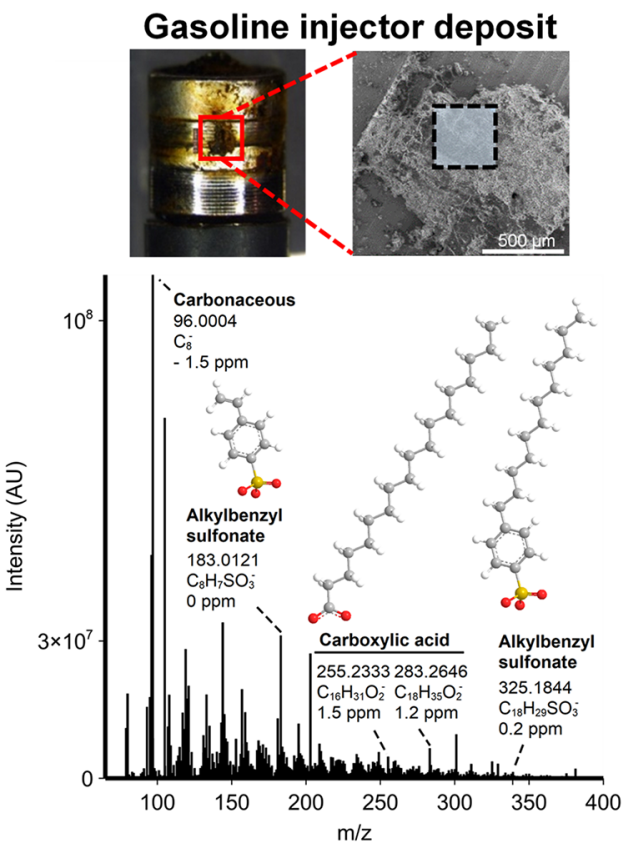

b

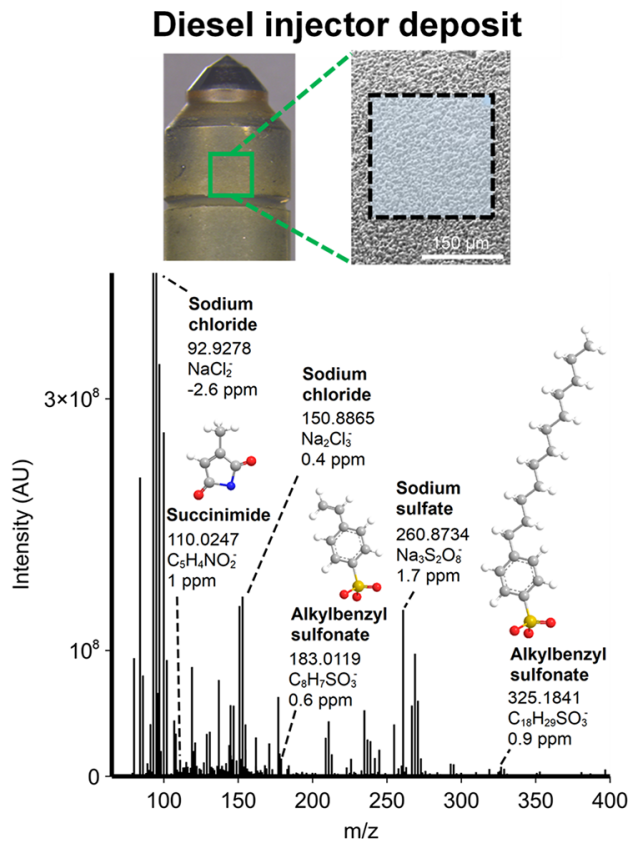

C

\section{Diesel filter deposit}
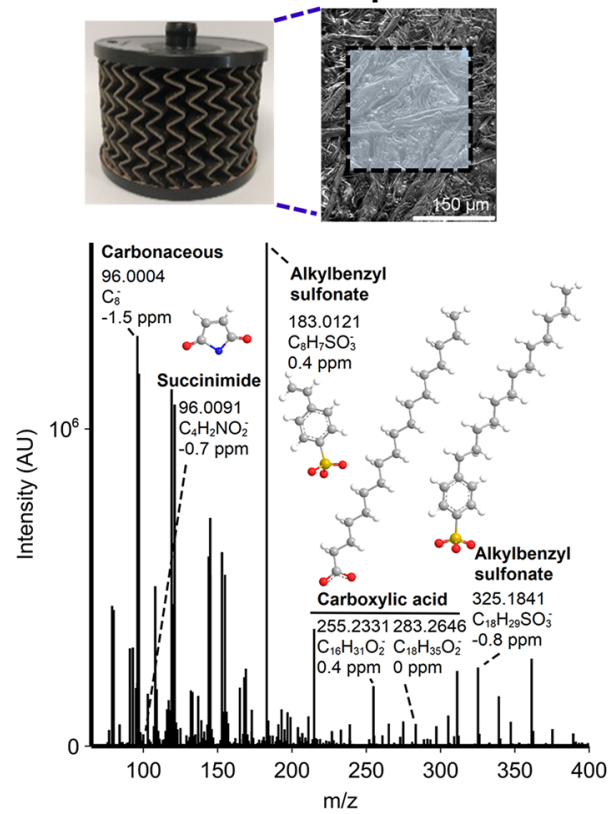

Figure 1. Identifying key molecular species in insoluble deposits with 3D OrbiSIMS. Photograph and inset SEM micrograph (above) and 3D OrbiSIMS depth profile accumulation ion data in negative polarity (below) of the (a) gasoline injector, (b) diesel injector, and (c) diesel filter deposit samples. Negative ion data for key deposit contributors are displayed with suggested chemical structures.

(diesel filter). The step energy was $1 \mathrm{eV}$ for the gasoline and diesel injector deposits and $0.5 \mathrm{eV}$ for diesel filter. Acquisition times were 3, 10 , and $20 \mathrm{~min}$ for the gasoline deposit, diesel injector, and diesel filter deposits, respectively. The spectra were charge corrected to the surface $\mathrm{C} 1 \mathrm{~s}$ peak (adventitious carbon) set to $285 \mathrm{eV}$ and used to estimate the total atomic \% of the detected elements using CasaXPS (version 2.3.22 PR1.0) software. Peak positions were referenced to the XPS reference pages of XPSFitting, and regions were fitted using a GL30 (30\% Gaussian and 70\% Lorentzian) line shape and U2 Tougaard background.

Samples were mounted on a standard Kratos sample bar $(13 \mathrm{~cm} \times$ $1.5 \mathrm{~cm}$ ) using double-sided adhesive tape. They were exposed to vacuum in the instrument airlock overnight and placed on the sample stage for analysis. The tape was nonconducting, so the charge neutralizer filament was required to prevent sample surface charging.

The energy range of the XPS was calibrated using $\mathrm{Cu}, \mathrm{Ag}$, and $\mathrm{Au}$ samples. The resolution for the photoelectron detector is checked on the $\mathrm{Ag} 3 \mathrm{~d}_{5 / 2}$ peak FWHM of $<0.55 \mathrm{eV}$ at PE 20 in the hybrid slot mode. Instrument ultimate resolution is initially calibrated on the $\mathrm{Ni}$ Fermi edge $(80 \%-20 \% \Delta E)$ at a pass energy of $10 \mathrm{eV}$ by using the $110 \mu \mathrm{m}$ aperture and field-of-view 2 lens mode. The transmission function was calibrated using a clean gold sample for all lens modes and pass energies.

2.5. Scanning Electron Microscopy (SEM). SEM micrographs were acquired for all samples using a FEI Quanta 650 ESEM instrument. All sample analysis was performed in low vacuum $(60 \mathrm{~Pa})$ to prevent sample charging, with an incident energy of $20 \mathrm{kV}$. 
a
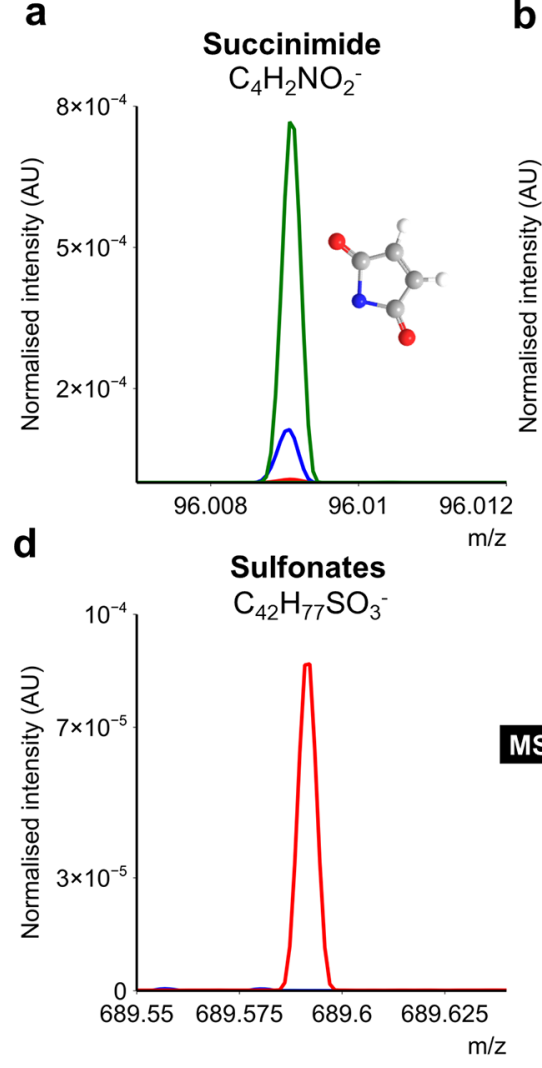

b

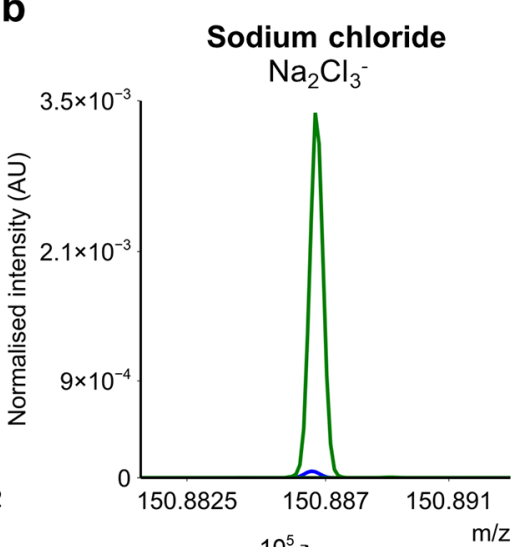

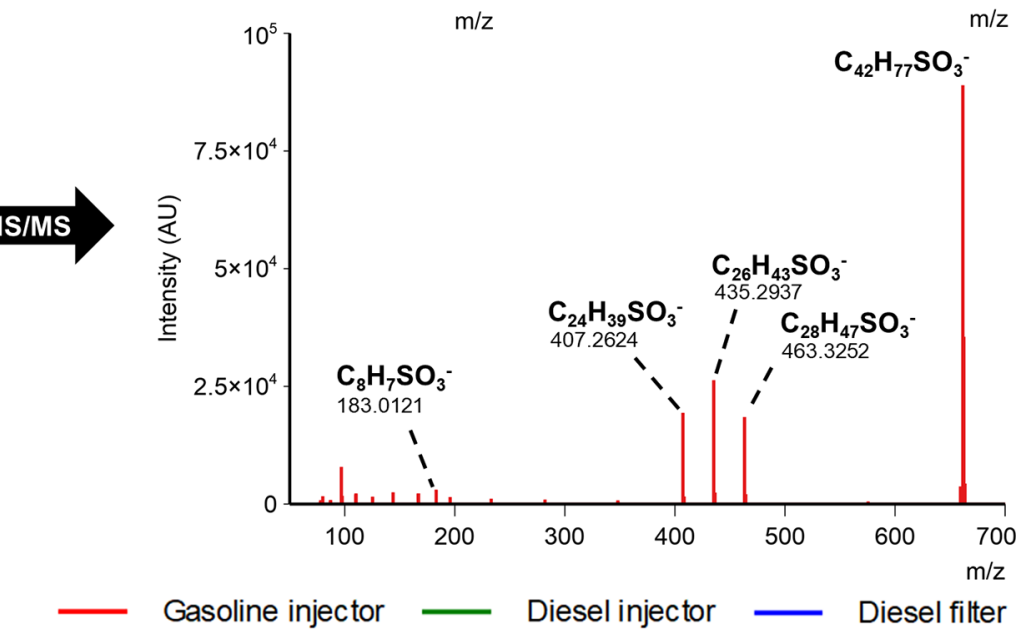

C

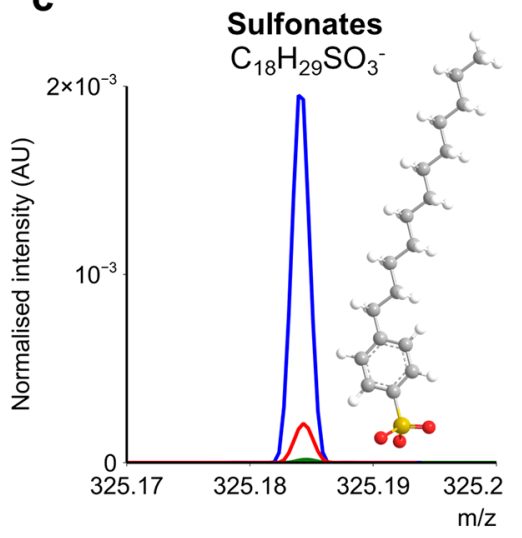

$\mathrm{C}_{42} \mathrm{H}_{77} \mathrm{SO}_{3}^{-}$

$\mathrm{m} / \mathrm{z}$

Figure 2. Normalized spectral comparison and MS/MS analysis of insoluble deposits. Comparison of ion intensities for representative ions for (a) succinimides $\left(\mathrm{C}_{4} \mathrm{H}_{2} \mathrm{NO}_{2}^{-}\right)$, (b) sodium chloride $\left(\mathrm{Na}_{2} \mathrm{Cl}_{3}^{-}\right)$, and (c) parent sulfonate ion $\left(\mathrm{C}_{18} \mathrm{H}_{29} \mathrm{SO}_{3}^{-}\right)$. (d) Spectra of a higher mass sulfonate ion $\left(\mathrm{C}_{42} \mathrm{H}_{77} \mathrm{SO}_{3}^{-}\right)$, unique to the gasoline deposit, and its subsequent fragmentation pattern from a higher energy collisional dissociation MS/MS experiment.

2.6. Optical Microscopy. Optical microscopy images of the gasoline and diesel injector deposit samples were taken with a Leica M205 FA Stereo light microscope.

2.7. Miscellaneous. Chemical structures were drawn in ChemDraw 14.0. Spectra and depth profiles presented in all figures were plotted using Veusz (Version 3.2.1, Jeremy Sanders).

\section{RESULTS AND DISCUSSION}

3.1. Identifying Key Molecular Species. Negative ion data acquired from a 3D OrbiSIMS depth profile of the three deposit samples in the range of $\mathrm{m} / z$ 75-400 are shown in Figure 1; we provide negative ion data above $m / z 400$ in Figure S1. Spectra were acquired from external surfaces of a gasoline direct injector component, a diesel injector component, and a diesel engine filter component recovered from real-world vehicles previously in operational service. SEM micrographs of the three deposits with the highlighted 3D OrbiSIMS analysis area are shown in Figure 1. Secondary ions were identified and grouped into compound classes, including alkylbenzyl sulfonates, succinimides, inorganic salts, dehydrogenated carbonaceous ion fragments, and $\mathrm{C}_{16}$ and $\mathrm{C}_{18}$ carboxylic acids. Putative structures are displayed, detailing their compound class, mass, and deviation (ppm). An extended list of the ions found in the samples with intensity data is given in Table S1.

Several alkylbenzyl sulfonate ions were present in all engine component deposits and were assigned with the generic formula of $\left[\mathrm{C}_{6} \mathrm{H}_{4}\left(\mathrm{SO}_{3}\right)\left(\mathrm{C}_{n} \mathrm{H}_{2 n+1}\right)\right]^{-}$, with a saturated hydro- carbon chain extending from the benzyl group (Figure $1 \mathrm{a}-\mathrm{c}$ ). In all deposits the dodecylbenzenesulfonate ion, $\mathrm{C}_{18} \mathrm{H}_{29} \mathrm{SO}_{3}{ }^{-}$ $\left[\mathrm{C}_{6} \mathrm{H}_{4}\left(\mathrm{SO}_{3}\right)\left(\mathrm{C}_{12} \mathrm{H}_{25}\right)\right]^{-}$, was present and is assumed to be representative of the intact species on the surface because it is cited as the specific molecule added to lubricant oil packages and is known to have a linear saturated hydrocarbon tail. 29,30 This was highest in normalized intensity in the diesel filter and is discussed later. One exception to the generic formula was the $\mathrm{C}_{8} \mathrm{H}_{7} \mathrm{SO}_{3}{ }^{-}(0 \mathrm{ppm})$ ion, containing a short unsaturated chain (Figure 1a). This is proposed to be a fragment of the parent ion $\left(\mathrm{C}_{18} \mathrm{H}_{29} \mathrm{SO}_{3}^{-}\right)$. Common to the samples were calcium sulfate ions such as $\mathrm{CaSO}_{4} \mathrm{H}^{-}$(Table S1), which likely correspond to sulfonates since calcium is the common counterion used in these additive packages. ${ }^{28}$ The presence of sulfonates in fuel-based deposits suggests residual lubricating oil is contaminating the fuel stream and is subsequently embedded in the deposit's matrix since the full parent ion was observed.

We observed several ions in all samples that corresponded to succinimide compounds with a short hydrocarbon chain from the succinimide functional group $\left(\mathrm{C}_{4} \mathrm{H}_{2} \mathrm{NO}_{2}{ }^{-}(-0.7 \mathrm{ppm})\right) .{ }^{18}$ Others include $\mathrm{C}_{5} \mathrm{H}_{4} \mathrm{NO}_{2}^{-}(-1 \mathrm{ppm})$ (Figure $1 \mathrm{~b}$ ), and they extended up to $\mathrm{C}_{12} \mathrm{H}_{16} \mathrm{NO}_{2}^{-}$(-1.7 ppm) (Table S1). Succinimides have several possible origins; low mass species such as those identified here are used in lubricating oil formulations, and the presence of lubricant-derived sulfonates points to this as a likely source. Inorganic salts present only in 
a

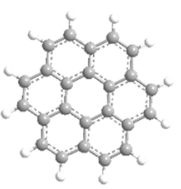

Coronene

$\mathrm{C}_{24} \mathrm{H}_{12}^{+}$

$\mathrm{m} / \mathrm{z} 300.0933$

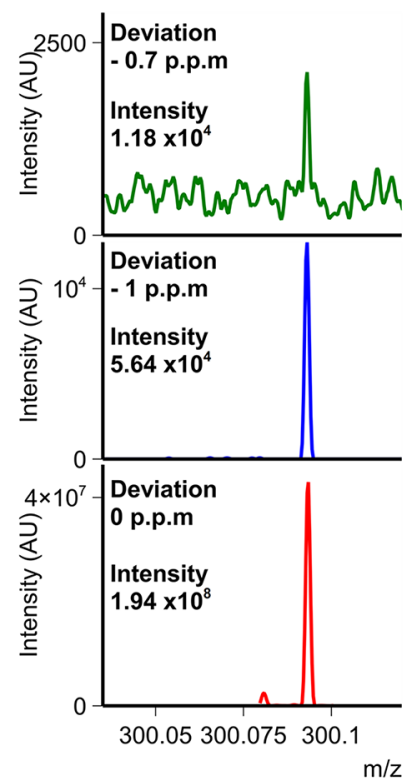

b

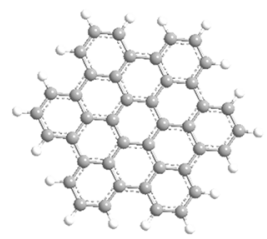

Hexabenzocoronene

$$
\mathrm{C}_{42} \mathrm{H}_{18}^{+}
$$

$\mathrm{m} / \mathrm{z} 522.1404$

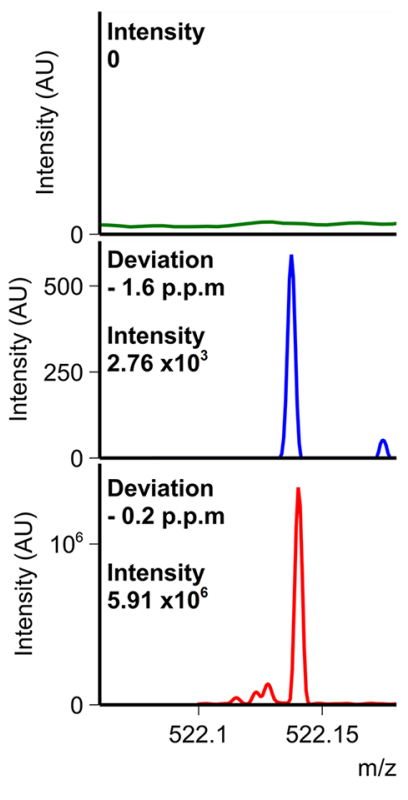

C

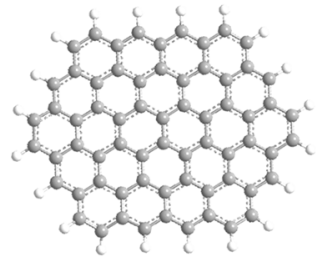

$\mathrm{C}_{66} \mathrm{H}_{20}^{+}$
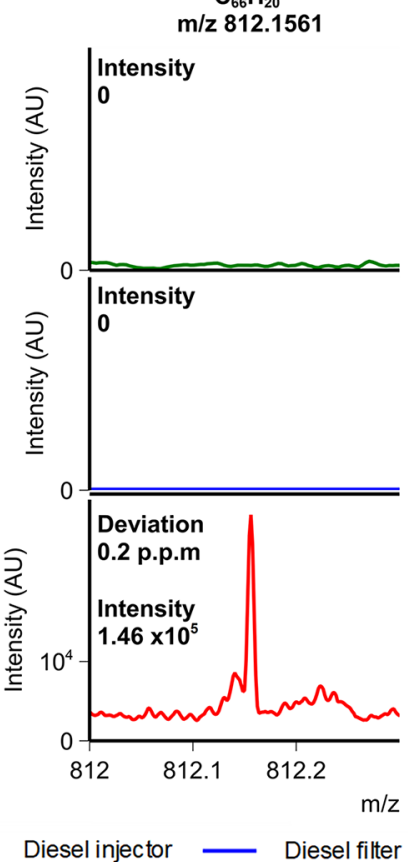

Figure 3. Molecular PAHs identified in the insoluble deposits. 3D structures for the three PAHs studied (above) and spectra of the PAH in each sample (below). (a) $\mathrm{C}_{24} \mathrm{H}_{12}{ }^{+}$(coronene, $m / z 300.093,1 \mathrm{ppm}$ ), (b) $\mathrm{C}_{42} \mathrm{H}_{18}{ }^{+}$(hexabenzocoronene, $m / z 522.140,1.6 \mathrm{ppm}$ ), and (c) $\mathrm{C}_{66} \mathrm{H}_{20}{ }^{+}(m / z$ 812.156, $0.2 \mathrm{ppm})$.

the diesel injector and filter deposit had various forms including sodium sulfate $\left(\mathrm{Na}_{3} \mathrm{SO}_{4}{ }^{+}, 1.3 \mathrm{ppm}\right)$, sodium hydroxide $\left(\mathrm{Na}_{3}(\mathrm{OH})_{2}{ }^{+}, 0.8 \mathrm{ppm}\right)$, and sodium chloride $\left(\mathrm{Na}_{2} \mathrm{Cl}_{3}{ }^{-}, 1.1 \mathrm{ppm}\right)$; these correlate to those previously identified in diesel deposits. ${ }^{31}$ A likely origin of inorganic salt contamination is from water bottoms present in fuel storage tanks. ${ }^{31,32}$ Negative ion data show dehydrogenated carbonaceous ions in all samples with the formula of $\mathrm{C}_{n}{ }^{-}$, such as $\mathrm{C}_{8}{ }^{-}$ $(1.5 \mathrm{ppm})$. These fragment ions are known to originate from highly conjugated dehydrogenated environments in SIMS analysis, such as from graphitic materials. ${ }^{33}$

Two ions, $\mathrm{C}_{16} \mathrm{H}_{31} \mathrm{O}_{2}{ }^{-}$and $\mathrm{C}_{18} \mathrm{H}_{35} \mathrm{O}_{2}{ }^{-}$, were assigned as $\mathrm{C}_{16}$ and $\mathrm{C}_{18}$ saturated linear carboxylic acids and were only present in the gasoline injector and diesel filter component deposit (Figure 1a,c). These have been identified in diesel deposits previously but not in gasoline deposits and are cited as being used in corrosion inhibitor fuel additive packages. ${ }^{19}$ We identified unsaturated $\mathrm{C}_{x} \mathrm{H}_{y} \mathrm{O}^{-}$ions and distinguished them from carboxylic acid fragments due to their different depth profiles; these are likely primary ion induced fragments of sulfonates (Figure S2). Finally, $\mathrm{C}_{x} \mathrm{H}_{y} \mathrm{O}_{z}{ }^{-}$ions were present in both polarity spectra of the diesel filter deposit and originate from the blank filter material (Table S1). This was confirmed after 3D OrbiSIMS analysis of a blank filter control sample (Figure S3).

3.2. Relative Contributions of Key Molecular Species. To compare relative contributions of key molecular species to the three component deposits, we display normalized 3D OrbiSIMS spectra of representative ions for succinimides, inorganic salts, and sulfonates in Figure 2, including MS/MS analysis to support putative assignments.

The succinimide ion $\left(\mathrm{C}_{4} \mathrm{H}_{2} \mathrm{NO}_{2}^{-}\right)$is significant for the diesel injector and filter deposit but of low intensity for the gasoline deposit, so is likely a minor contributor in this sample (Figure 2a). We evidence high levels of sodium chloride salt contamination in the diesel injector deposit, exemplified by $\mathrm{Na}_{2} \mathrm{Cl}_{3}^{-}(0.8 \mathrm{ppm})$; this is not evident in the gasoline deposit (Figure $2 \mathrm{~b}$ ). The sulfonate parent ion had the highest intensity in the diesel filter and was lowest in the diesel injector deposit (Figure 2c). This shows the filter deposit has the highest levels of sulfonate contamination, whereas the diesel injector deposits chemistry is predominately salt based.

Sulfonates above the mass of the native compound added to lubricating oil packages $\left(\mathrm{C}_{18} \mathrm{H}_{29} \mathrm{SO}_{3}^{-}\right)$were present in the gasoline deposit including $\mathrm{C}_{42} \mathrm{H}_{77} \mathrm{SO}_{3}{ }^{-}\left[\mathrm{C}_{6} \mathrm{H}_{4}\left(\mathrm{SO}_{3}\right)\right.$ $\left.\left(\mathrm{C}_{36} \mathrm{H}_{73}\right)\right]^{-}$and $\mathrm{C}_{74} \mathrm{H}_{141} \mathrm{SO}_{3}{ }^{-}\left[\mathrm{C}_{6} \mathrm{H}_{4}\left(\mathrm{SO}_{3}\right)\left(\mathrm{C}_{68} \mathrm{H}_{137}\right)\right]^{-}$ (Table S1). MS/MS analysis of $\mathrm{C}_{42} \mathrm{H}_{77} \mathrm{SO}_{3}{ }^{-}$showed fragmentation corresponding to loss of the saturated alkyl chain to varying degrees (Figure $2 \mathrm{~d}$ ). Despite the saturated parent molecule, fragmented ions all show one site of unsaturation on the alkyl bond adjacent to the benzyl group (Table S2) and are likely stable products in the SIMS fragmentation process and are similar to the intense $\mathrm{C}_{8} \mathrm{H}_{7} \mathrm{SO}_{3}{ }^{-}$ ion (Figure 1). The presence of higher mass sulfonates 
suggests the deposited residue is undergoing transformation to form extended structures in the component deposit itself. Combination of the native sulfonate and linear fuel derived hydrocarbon chains, for example, octane, $\mathrm{C}_{74} \mathrm{H}_{141} \mathrm{SO}_{3}{ }^{-}=$ $\mathrm{C}_{18} \mathrm{H}_{29} \mathrm{SO}_{3}{ }^{-}+\left(\mathrm{C}_{8} \mathrm{H}_{16}\right)_{7}$, and $\mathrm{C}_{42} \mathrm{H}_{77} \mathrm{SO}_{3}{ }^{-}=\mathrm{C}_{18} \mathrm{H}_{29} \mathrm{SO}_{3}^{-}+$ $\left(\mathrm{C}_{8} \mathrm{H}_{16}\right)_{3}$ explains the mass difference between both types of sulfonate ions. This likely proceeds through a free-radical mechanism, ${ }^{34}$ and is promoted by the high temperatures of the combustion chamber, which only the gasoline injector component was exposed to. It is possible that these higher mass species have a branched or linear hydrocarbon chain, but from MS/MS data we can only determine that the long chain is saturated aside from the bond connecting the benzyl group and hydrocarbon chain. These species were not observed in either diesel deposit since they were exposed to a lower temperature. This shows deposit composition is impacted by the addition of native chemical species and from reactivity of such species in the deposit itself.

3.3. Polycyclic Aromatic Hydrocarbons (PAHs). Positive polarity spectra (Figure S4) showed more complete fragments of carbonaceous structures than negative ion data, particularly for PAHs. Their presence in diesel and gasoline insoluble deposits has been previously inferred by researchers in this field ${ }^{21,24}$ but here were unequivocally assigned for the first time in insoluble deposits. PAHs, particularly those of high mass, are likely derived from the breakdown products of fuel constituents; the high temperatures and pressures experienced by the engine components facilitate this reactivity through aromatization. ${ }^{35}$ As a result of fuel recirculation, it is likely that the filter may also be exposed to the products of this breakdown. We identified different maximum masses in the three engine component deposits: $\mathrm{m} / z 800$ in the gasoline deposit, $\mathrm{m} / z 300$ in the diesel injector deposit, and $\mathrm{m} / z 550$ in the diesel filter deposit; positive ion data are shown in Figure 3.

PAHs exist as radical cations and correspond to known structures previously identified from environmental sources. ${ }^{36}$ Coronene $\left(\mathrm{C}_{24} \mathrm{H}_{12}{ }^{+}, 1.0 \mathrm{ppm}\right)$ was present on all three components but with low intensity on the diesel injector (Figure 3a). Hexabenzocoronene $\left(\mathrm{C}_{42} \mathrm{H}_{18}{ }^{+}, 1.6 \mathrm{ppm}\right)$ was absent in the diesel injector; we observed a high intensity peak from the gasoline deposit for this ion (Figure $3 \mathrm{~b}$ ). High mass PAHs $\left(\mathrm{C}_{66} \mathrm{H}_{20}{ }^{+}, 0.2 \mathrm{ppm}\right.$ ) (Figure $3 \mathrm{c}$ ) were present only in the gasoline deposit and suggest that considerably larger aromatic structures are being formed in this deposit. This maximum mass ion is comparable to some of the largest PAHs detected in coal tar pitch by other high-resolution MS techniques ${ }^{37}$ and far larger than those inferred by time-of-flight SIMS in previous deposit analyses. $^{24}$ The difference between PAH maximum mass was attributed to the location of the component in the engine. The higher temperatures experienced by the gasoline injector component likely promote extensive aromatization of fuel derived material in the resultant deposit to these extended structures. PAH growth from fuel in high-temperature environments has been previously postulated to occur ${ }^{38}$ but has not been evidenced to date. It is worth noting we performed three analytical repeats using different areas of each sample and observed the same differences between the samples (data not shown).

3.4. Elemental Surface Analysis. SIMS analysis is not inherently quantitative because the different ionization and sputtering of different species are difficult to account for. Thus, we employed XPS to provide estimates of the elemental composition (\%) of the three deposits (ca. $10 \mathrm{~nm}$ deep). We performed a subsurface analysis on the gasoline and diesel injector deposits by first sputtering with an argon gas cluster ion beam to remove adventitious carbon and contaminants from the surface; this was not viable for the diesel filter deposit due to the porous nature of the fibrous material. Survey XPS spectra are presented in Figure 4 alongside a table quantifying

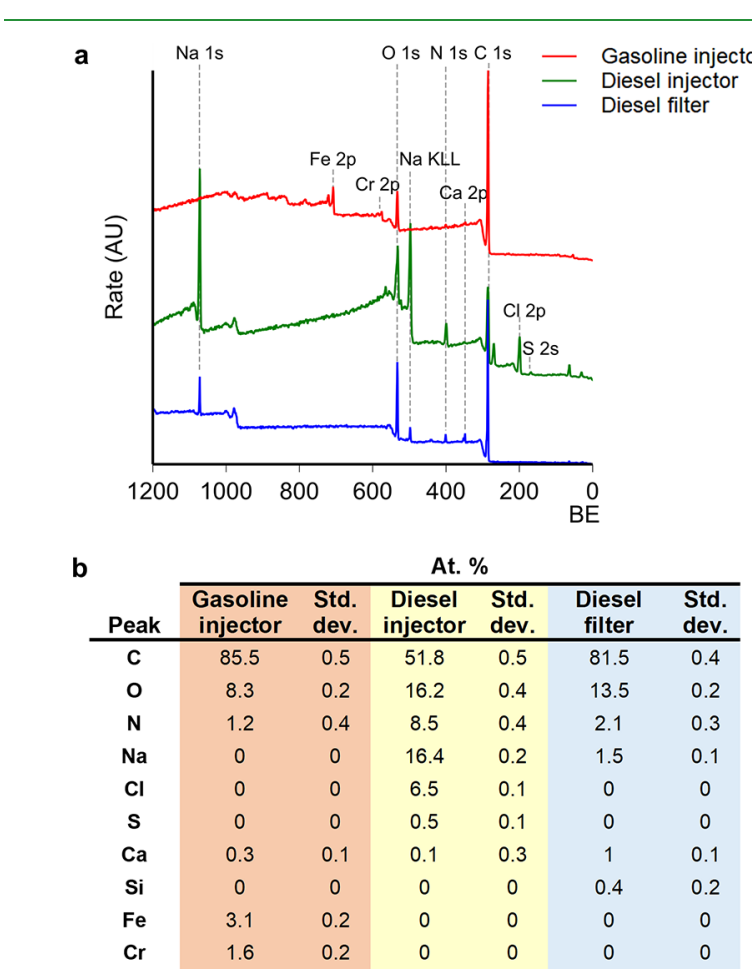

Figure 4. Elemental surface analysis of deposits via XPS. (a) Overlaid spectra of the samples. (b) Quantification of the composition of each deposit with errors presented as standard deviation (std dev). $\mathrm{BE}=$ binding energy.

the elemental compositions. We calculated standard deviations using a Monte Carlo simulation which are displayed in (Table $\mathrm{S} 3)$; in all cases the largest error was of the $\mathrm{C} 1 \mathrm{~s}$ peak and was $<0.5 \%$.

The gasoline injector and diesel filter deposit have a significantly higher carbon concentration than the diesel injector deposit; both diesel deposits had high levels of sodium, oxygen, and nitrogen. Salt deposition was highest in the diesel injector deposit, with a sodium concentration of $16.4 \%$ (Figure 4). The concentration of chlorine in this sample (6.5\%) suggests that $\sim 40 \%$ of the inorganic salt present here is sodium chloride. Evidently other counterions are present in this sample and the diesel filter deposit and correlate with the higher amounts of oxygen and nitrogen. We identified other ions from the 3D OrbiSIMS data for both diesel deposits including sulfates, hydroxides, carbonates $\left(\mathrm{Na}_{3} \mathrm{CO}_{3}{ }^{+}\right)$, nitrites $\left(\mathrm{Na}\left(\mathrm{NO}_{2}\right)_{2}{ }^{-}\right)$, and cyanates $\left(\mathrm{Na}_{3}(\mathrm{CNO})_{2}{ }^{+}\right)$(Table S1). Sodium cyanate was only present in the diesel injector and had a relatively high normalized intensity; its 1:1 nitrogenoxygen ratio partly explains the similar offset of these elements between the gasoline and diesel injector deposits elemental composition (Figure 4b). Sulfate salts are attributed as the origin of sulfur in the diesel injector deposit; this correlates with the high sodium levels and is unlikely to originate from sulfonates due to its low relative intensity for this sample in the SIMS spectra (Figure 2). The lack of sulfur in the other 
samples suggests sulfonates exist below the detection limits of XPS analysis, despite their prevalence in the 3D OrbiSIMS spectra. Calcium has several possible sources as it is used as the cation in a variety of detergent additives and can be present in high quantities in lubricating oil formulations. ${ }^{39}$ The high amounts in the diesel filter correlates with the normalized 3D OrbiSIMS spectra (Figure 2) and suggests this component was exposed to the highest levels of lubricant oil contamination. Silicon was present in the diesel filter and was attributed to silicone surface contamination. Finally, the gasoline deposit showed low concentrations of iron and chromium. This likely relates to areas of exposed clean metal substrate scanned during XPS analysis; Figure 1a shows the rough "patchy" topography of the gasoline deposit. A comprehensive list of XPS peaks (\% and standard deviation) is presented in Table S3.

3.5. Combined Depth Profiling and Chemical Imaging. Positive and negative 3D OrbiSIMS data acquired from a combined chemical imaging and depth profiling experiment on the gasoline and diesel injector deposits are detailed in Figure 5 and 6, respectively. We display data for key molecular species

a

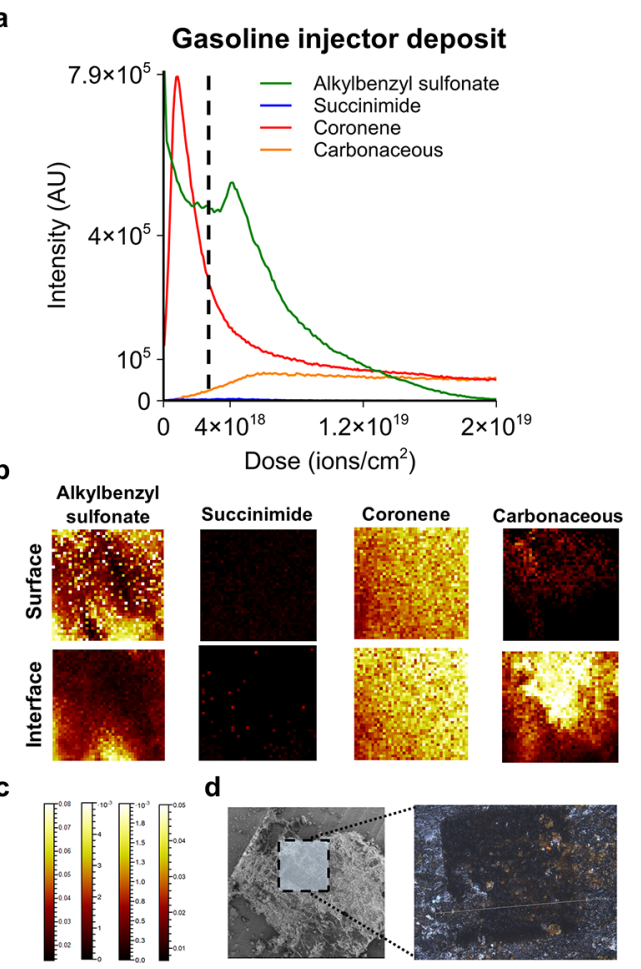

Figure 5. Combined $\mathrm{Ar}_{3000}{ }^{+}$depth profiling and chemical imaging of a gasoline fuel injector deposit. (a) Depth profiles of key diagnostic ions. (b) Chemical images of these ions, taken at the surface and a lower depth (interface). (c) Scale bars for chemical images for alkylbenzyl sulfonates, succinimide, coronene, and a carbonaceous ion (left to right). (d) Optical profilometry image of the resultant crater after sputtering. Chemical images were normalized to the total ion image and cropped to a $200 \times 200 \mu \mathrm{m}^{2}$ area.

including sulfonates $\left(\mathrm{C}_{8} \mathrm{H}_{7} \mathrm{SO}_{3}{ }^{-}\right)$, PAHs (coronene, $\mathrm{C}_{24} \mathrm{H}_{12}{ }^{+}$), succinimides $\left(\mathrm{C}_{4} \mathrm{H}_{2} \mathrm{NO}_{2}^{-}\right)$, a carbonaceous ion $\left(\mathrm{C}_{8}^{-}\right)$, and sodium chloride $\left(\mathrm{Na}_{2} \mathrm{Cl}_{3}^{-}\right)$.

The gasoline deposit depth profile shows sulfonates were prevalent at multiple depths but were most intense at the outer surface (Figure 5a). The surface localization of these species suggests a low thermal stability, prompting breakdown shortly a

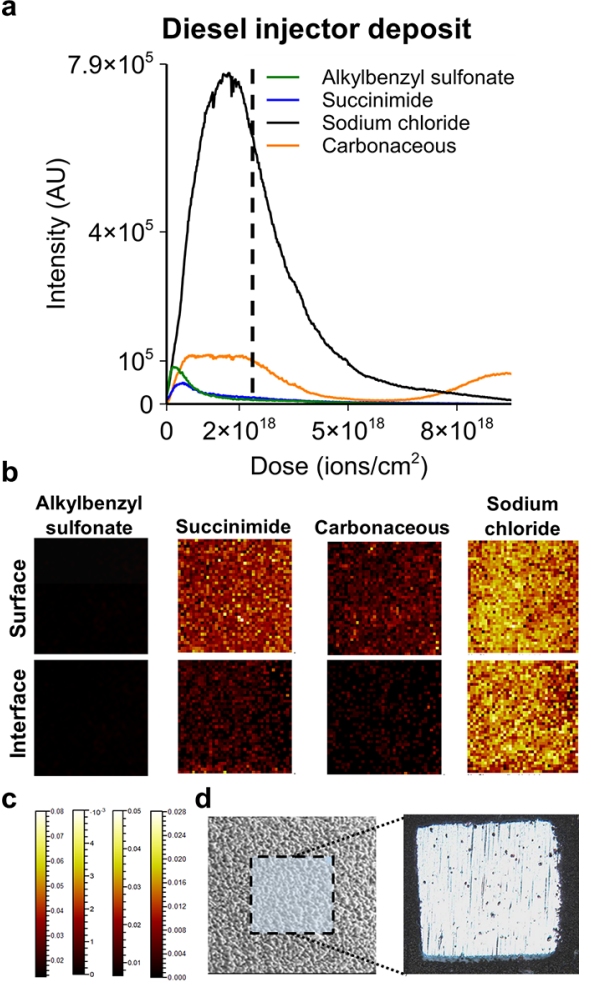

Figure 6. Combined $\mathrm{Ar}_{3000}{ }^{+}$depth profiling and chemical imaging of a diesel injector deposit. (a) Depth profiles of key diagnostic ions. (b) Chemical images of these ions, taken at the surface and a lower depth (interface). (c) Scale bars for chemical images for alkylbenzyl sulfonates, succinimide, a carbonaceous ion, and sodium chloride (left to right). (d) Optical profilometry image of the resultant crater after sputtering. Chemical images were normalized to the total ion image and cropped to a $200 \times 200 \mu \mathrm{m}^{2}$ area.

after deposition on the engine component. During profiling, the gas cluster ion source could not sputter through the interface exposed after $10^{4} \mathrm{~s}$, which correlates with the profile of carbonaceous ions such as $\mathrm{C}_{8}^{-}$. This interface is shown from optical profilometry imaging in Figure $5 \mathrm{~d}$. The plateauing depth profile of this ion in the gasoline deposit compared with the highest mass $\mathrm{PAH}$ identified, $\mathrm{C}_{66} \mathrm{H}_{20}{ }^{+}$(Figure S5), shows the $\mathrm{C}_{n}{ }^{-}$ions originate from a layer lower than these high mass PAHs. We employed chemical imaging to study the lateral distribution of ions at the surface and at a lower deposit depth after argon gas cluster ion beam profiling (Figure $5 \mathrm{~b}$ ). Sulfonates had high intensity at both deposit depths in the gasoline injector deposit and are distributed nonuniformly; this correlates with lubricant-derived sulfonates being a localized trace contaminant and so are not part of the carbonaceous matrix. Conversely, coronene was uniformly distributed at both depths and illustrates its contribution to the organic matrix and correlates with their suggested origin of fuel derived material in the gasoline deposit.

The offset between sulfonates and succinimide ion intensity is far less in the diesel injector deposit than the gasoline deposit (Figures 5a and 6a), evidencing an increased contribution from sulfonates over the entire deposit depth. The sodium chloride salt ion dominated the chemistry of the diesel injector deposit with a high intensity throughout and suggests sodium salt contamination over multiple fueling cycles (Figure 6a). An important distinction between the samples is the intensity of coronene, with an increasing intensity 
throughout the gasoline deposit depth and an insignificant intensity in the diesel injector deposit. This correlates with the data presented in Figure 3 which shows a lower PAH contribution to the diesel injector. The diesel injector deposit also exhibited a shiny surface after sputtering, marking the substrate (Figure $6 \mathrm{~d}$ ). This layer also correlates with the profile $\mathrm{C}_{8}{ }^{-}$in this sample (Figure 6a) and here is thought to originate from a diamond-like coating placed above the diesel injector substrate during manufacturing. These are used to try and prevent deposit formation on the substrate. ${ }^{24,40}$

Chemical imaging of the diesel deposit showed delocalized distributions of all targeted ions (Figure $6 \mathrm{~b}$ ). The fact that sodium chloride salt illustrated a homogeneous lateral distribution at both deposit depths suggests that this deposit experienced a high contribution from inorganic salts, agreeing with XPS data (Figure 4). Comparison of samples shows different distributions of carbonaceous ions; the gasoline deposit illustrated a localized distribution of carbonaceous material at the lowest deposit depth (Figure 5b), unlike the diesel injector deposit (Figure 6b). In the first case, this layer is likely indicative of dehydrogenated carbonaceous material and suggests the gasoline deposit is built up from an initial deposition of fuel followed by reactivity to form PAHs of varying mass and then undergoing further condensation to form a dehydrogenated graphitic-like material in the deepest layers. This has been previously postulated in this field ${ }^{23,38}$ but is evidenced here from the insights afforded by diagnostic 3D OrbiSIMS data.

3.6. Conclusions. In this work we demonstrated the capabilities of 3D OrbiSIMS with its high mass resolving power and MS/MS capabilities to unambiguously uncover the identity and 3D spatial distribution of key molecular components in insoluble deposits formed upon internal combustion engine components. Molecular speciation informed us of specific origins of deposit components including lubricant oil residues, combustion products, and sodium salts. We evidenced reactions between fuel and specific lubricating oil constituents on the surface of the gasoline deposit, which highlights the important influence of temperature on overall deposit composition. Depth profiling and chemical imaging gave new evidence into the chemical transformations that contribute to deposit formation such as aromatization to form PAHs and carbonaceous clusters in the lowest depths of the gasoline deposit-previously only speculated to occur in these systems. Quantitative elemental analysis proved valuable to show the prevalence of constituents, such as high levels of sodium salts in the diesel injector deposit. Evidence of a diamond like coating on this component suggests that it does not adequately protect against these salt-type deposits and highlights the importance of using a fuel stream free of these contaminants. Our findings take a significant step toward deposit mitigation. Several strategies can be employed to realize this such as implementing stricter worldwide fuel specifications, modifying additives which show adverse reactivity and synthesizing new deposit control additives to solubilize deposits in the engine. This will help to ensure the efficiency of internal combustion engines in the long term and reduce air pollution.

\section{ASSOCIATED CONTENT}

\section{SI Supporting Information}

The Supporting Information is available free of charge at https://pubs.acs.org/doi/10.1021/acsami.0c14532.
Figure S1: 3D OrbiSIMS negative ion data over six mass ranges for each sample in the range of $\mathrm{m} / z$ 400-1100 Da for each sample; Figure S2: 3D OrbiSIMS depth profiles comparing depth behavior of carboxylic acids, sulfonates, and related secondary ion fragments; Figure S3: 3D OrbiSIMS negative ion data obtained from a blank diesel fuel filter medium and assignments for oxygenated ions that were also found in the deposit; Figure S4: 3D OrbiSIMS positive ion data over six mass ranges between 75 and $1100 \mathrm{Da}$ for each sample; Figure S5. 3D OrbiSIMS depth profiles of the PAHs and a carbonaceous ion; Table S1: 3D OrbiSIMS ion table for ions identified in deposit samples; Table S2: MS/MS ion table of the high mass sulfonate ion at $\mathrm{m} / z$ 661.5957; Table S3: subsurface XPS results (PDF)

\section{Accession Codes}

Data can be found in the University of Nottingham data repository at http://doi.org/10.17639/nott.7058.

\section{AUTHOR INFORMATION}

\section{Corresponding Author}

David J. Scurr - School of Pharmacy, University of Nottingham, Nottingham NG7 2RD, U.K.; $\odot$ orcid.org/0000-0003-08593886; Email: David.Scurr@nottingham.ac.uk

\section{Authors}

Max K. Edney - Department of Chemical and Environmental Engineering, University of Nottingham, Nottingham NG7 2RD, U.K.; $\odot$ orcid.org/0000-0003-3438-5060

Joseph S. Lamb - Department of Chemical and Environmental Engineering, University of Nottingham, Nottingham NG7 2RD, U.K.

Matteo Spanu - Department of Chemical and Environmental Engineering, University of Nottingham, Nottingham NG7 2RD, U.K.

Emily F. Smith - Nanoscale and Microscale Research Centre, University of Nottingham, Nottingham NG7 2RD, U.K.

Elisabeth Steer - Nanoscale and Microscale Research Centre, University of Nottingham, Nottingham NG7 2RD, U.K.

Edward Wilmot - Innospec Ltd., Ellesmere Port, Cheshire CH65 4EY, U.K.

Jacqueline Reid - Innospec Ltd., Ellesmere Port, Cheshire CH65 $4 E Y$, U.K.

Jim Barker - Innospec Ltd., Ellesmere Port, Cheshire CH65 4EY, U.K.

Morgan R. Alexander - School of Pharmacy, University of Nottingham, Nottingham NG7 2RD, U.K.

Colin E. Snape - Department of Chemical and Environmental Engineering, University of Nottingham, Nottingham NG7 2RD, U.K.

Complete contact information is available at:

https://pubs.acs.org/10.1021/acsami.0c14532

\section{Author Contributions}

J.B., D.J.S., and C.E.S. planned and coordinated the project. M.K.E., J.S.L., D.J.S., and M.S. conducted 3D OrbiSIMS experiments. E.F.S. collected XPS data. M.K.E., J.S.L., M.S., and E.S. collected SEM micrographs. M.K.E., J.B., J.S.L., D.J.S., C.E.S., E.F.S., M.S., E.S., and E.W. interpreted the analytical data. M.K.E. wrote the manuscript. All authors helped in editing the manuscript. 


\section{Notes}

The authors declare no competing financial interest.

\section{ACKNOWLEDGMENTS}

We thank David Knight at Innospec Ltd. for breaking open the gasoline and diesel injectors for analysis. This research is funded and supported by the Engineering and Physical Sciences Research Council (EPSRC) and Innospec Ltd. The project is part of the Centre for Doctoral Training in Carbon Capture and Storage and Cleaner Fossil Energy (EPSRC grant $\mathrm{EP} / \mathrm{L} 016362 / 1)$. The EPSRC is also gratefully acknowledged for the Strategic Equipment grant "3D OrbiSIMS: Label free chemical imaging of materials, cells and tissues" funding that supported this work (grant EP/P029868/1).

\section{ABBREVIATIONS}

3D OrbiSIMS, Orbitrap secondary ion mass spectrometry; $\mathrm{PAH}$, polycyclic aromatic hydrocarbon; XPS, X-ray photoelectron spectroscopy.

\section{REFERENCES}

(1) Bloomberg New Energy Finance. Electric Vehicle Outlook, 2019.

(2) House of Commons: Business Energy and Industrial Strategy Committee. Electric vehicles: driving the transition, 2018.

(3) Kalghatgi, G. Is it really the end of internal combustion engines and petroleum in transport? Appl. Energy 2018, 225, 965-974.

(4) Moriarty, P.; Wang, S. J. Can Electric Vehicles Deliver Energy and Carbon Reductions? Energy Procedia 2017, 105, 2983-2988.

(5) Reitz, R D; Ogawa, H; Payri, R; Fansler, T; Kokjohn, S; Moriyoshi, Y; Agarwal, A.; Arcoumanis, D; Assanis, D; Bae, C; Boulouchos, K; Canakci, M; Curran, S; Denbratt, I; Gavaises, M; Guenthner, M; Hasse, C; Huang, Z; Ishiyama, T; Johansson, B; Johnson, T.; Kalghatgi, G; Koike, M; Kong, S.; Leipertz, A; Miles, P; Novella, R; Onorati, A; Richter, M; Shuai, S; Siebers, D; Su, W; Trujillo, M; Uchida, N; Vaglieco, B M; Wagner, R.; Zhao, H IJER editorial: The Future of the Internal Combustion Engine. Int. J. Engine Res. 2020, 21, 3-10.

(6) Moawad, A.; Kim, N.; Shidore, N.; Rousseau, A. Assessment of Vehicle Sizing, Energy Consumption, and Cost through Large-Scale Simulation of Advanced Vehicle Technologies, 2016.

(7) Gabiña, G.; Martin, L.; Basurko, O. C.; Clemente, M.; Aldekoa, S.; Uriondo, Z. Performance of Marine Diesel Engine in Propulsion Mode with a Waste oil-based Alternative Fuel. Fuel 2019, 235, 259268.

(8) Llamas, X.; Eriksson, L. Control-oriented modeling of two-stroke diesel engines with exhaust gas recirculation for marine applications. Proc. Inst. Mech. Eng. Part M J. Eng. Marit. Environ. 2019, 233, 551574.

(9) Barker, J.; Reid, J.; Mulqueen, S.; Langley, G. J.; Wilmot, E. M. J.; Vadodaria, S.; Castle, J.; Whitaker, J. The Investigation of the Structure and Origins of Gasoline Direct Injection (GDI) Deposits. SAE Tech. Pap. Ser. 2019, DOI: 10.4271/2019-01-2356.

(10) Xu, H.; Wang, C.; Ma, X.; Sarangi, A. K.; Weall, A.; KruegerVenus, J. Fuel Injector Deposits in Direct-Injection Spark-Ignition Engines. Prog. Energy Combust. Sci. 2015, 50, 63-80.

(11) Behrendt, C.; Smith, A. A Study of Diesel Fuel Injector Deposit Effects on Power and Fuel Economy Performance. SAE Tech. Pap. Ser. 2017, DOI: $10.4271 / 2017-01-0803$.

(12) Wen, Y.; Wang, Y.; Fu, C.; Deng, W.; Zhan, Z.; Tang, Y.; Li, X.; Ding, H.; Shuai, S. The Impact of Injector Deposits on Spray and Particulate Emission of Advanced Gasoline Direct Injection Vehicle. SAE Tech. Pap. Ser. 2016, DOI: 10.4271/2016-01-2284.

(13) Jiang, C.; Xu, H.; Srivastava, D.; Ma, X.; Dearn, K.; Cracknell, R.; Krueger-Venus. Effect of Fuel Injector Deposit on Spray Characteristics, Gaseous Emissions and Particulate Matter in a Gasoline Direct Injection Engine. Appl. Energy 2017, 203, 390-402.
(14) Henkel, S.; Hardalupas, Y.; Taylor, A.; Conifer, C.; Cracknell, R.; Goh, T. K.; Reinicke, P. B.; Sens, M.; Rieß, M. Injector Fouling and Its Impact on Engine Emissions and Spray Characteristics in Gasoline Direct Injection Engines. SAE Int. J. Fuels Lubr. 2017, 10, 287-295.

(15) Zhang, W.; Ma, X.; Xinhui, L.; Shuai, S. Impact of Fuel Properties on GDI Injector Deposit Formation and Particulate Matter Emissions. SAE Tech. Pap. Ser. 2020, DOI: 10.4271/2020-01-0388.

(16) World Health Organization. Air Pollution. Available at https:// www.who.int/health-topics/air-pollution\#tab=tab_1 (Accessed: 18th November 2019).

(17) Edney, M. K.; Barker, J.; Reid, J.; Scurr, D. J.; Snape, C. E. Recent Advances in the Analysis of GDI and Diesel Fuel Injector Deposits. Fuel 2020, 272, 117682.

(18) Barker, J., Reid, J., Snape, C., Scurr, D.; Meredith, W. Spectroscopic Studies of Internal Injector Deposits (IDID) Resulting from the Use of Non-Commercial Low Molecular Weight Polyisobutylenesuccinimide (PIBSI). (2014, 7, 762. .

(19) Technical Committee of Petroleum Additive Manufacturers in Europe. Fuel Additives: Uses and Benefits. ATC Europe, 2013. Available at https://www.atc-europe.org/public/Doc1132013-11-20. pdf (Accessed: 21st November 2018).

(20) Cardenas, D.; Esperilla, O.; Manzanero, F.; Duarte, Y.; Toscano, L.; Wolff, G. Internal Diesel Injector Deposits: Sodium Carboxylates of C12 Succinic Acids and C16 and C18 Fatty Acids. SAE Tech. Pap. Ser. 2012, DOI: 10.4271/2012-01-1689.

(21) Venkataraman, R.; Eser, S. Characterization of deposits formed on diesel injectors in field test and from thermal oxidative degradation of $\mathrm{n}$-hexadecane in a laboratory reactor. Chem. Cent. J. 2008, 2, 25.

(22) Vickerman, J. C.; Gilmore, I. S. Surface Analysis: The Principal Techniques; Wiley: 2011.

(23) Barker, J.; Snape, C.; Scurr, D. A Novel Technique for Investigating the Characteristics and History of Deposits Formed Within High Pressure Fuel Injection Equipment. SAE Int. J. Fuels Lubr. 2012, 5, 1155-1164.

(24) Barker, J., Snape, C.; Scurr, D. Information on the Aromatic Structure of Internal Diesel Injector Deposits From Time of Flight Secondary Ion Mass Spectrometry (ToF-SIMS). In SAE 2014 World Congress \& Exhibition; SAE International: 2014.

(25) Feld, H.; Oberender, N. Characterization of Damaging Biodiesel Deposits and Biodiesel Samples by Infrared Spectroscopy (ATR-FTIR) and Mass Spectrometry (TOF-SIMS), 2016.

(26) Passarelli, M. K.; Pirkl, A.; Moellers, R.; Grinfeld, D.; Kollmer, F.; Havelund, R.; Newman, C. F.; Marshall, P. S.; Arlinghaus, H.; Alexander, M. R.; West, A.; Horning, S.; Niehuis, E.; Makarov, A.; Dollery, C. T.; Gilmore, I. S. The 3D OrbiSIMS-Label-Free Metabolic Imaging with Subcellular Lateral Resolution and High Mass-Resolving Power. Nat. Methods 2017, 14, 1175.

(27) Seah, M. P.; Havelund, R.; Gilmore, I. S. Universal Equation for Argon Cluster Size-Dependence of Secondary Ion Spectra in SIMS of Organic Materials. J. Phys. Chem. C 2014, 118, 12862-12872.

(28) Technical Committee of Petroleum Additive Manufacturers in Europe. Lubricant Additives: Uses and Benefits, 2016.

(29) Nassar, A. M.; Ahmed, N. S.; El-shazly, R. I.; Abd el menem, Y. $K$. Preparation and evaluation of the mixtures of sulfonate and phenate as lube oil additives. Int. J. Ind. Chem. 2017, 8, 383-395.

(30) Geng, Y.; Huang, J.; Tan, B.; Xu, Y.; Li, P.; Xu, J. Efficient synthesis of Dodecylbenzene Sulfonic Acid in Microreaction Systems. Chem. Eng. Process. 2020, 149, 107858.

(31) Barker, J.; Cook, S.; Richards, P. Sodium Contamination of Diesel Fuel, its Interaction with Fuel Additives and the Resultant Effects on Filter Plugging and Injector Fouling, 2013.

(32) Schwab, S. D.; Bennett, J. J.; Dell, S. J.; Galante-Fox, J. M.; Kulinowski, A. M.; Miller, K. T. Internal Injector Deposits in HighPressure Common Rail Diesel Engines. SAE Int. J. Fuels Lubr. 2010, 3, 865-878.

(33) Xie, W.; Weng, L.-T.; Ng, K. M.; Chan, C. K.; Chan, C.-M. Defects of clean graphene and sputtered graphite surfaces 
characterized by time-of-flight secondary ion mass spectrometry and X-ray photoelectron spectroscopy. Carbon 2017, 112, 192-200.

(34) Boot, M. D.; Tian, M.; Hensen, E. J. M.; Mani Sarathy, S. Impact of fuel molecular structure on auto-ignition behavior - Design rules for future high performance gasolines. Prog. Energy Combust. Sci. 2017, 60, 1-25.

(35) Richter, H.; Howard, J. B. Formation of polycyclic aromatic hydrocarbons and their growth to soot-a review of chemical reaction pathways. Prog. Energy Combust. Sci. 2000, 26, 565-608.

(36) National Research Council (US) Committee on Pyrene and Selected Analogues. Polycyclic Aromatic Hydrocarbons: Evaluation of Sources and Effects; National Academies Press: 1983.

(37) Zhang, W.; Andersson, J. T.; Räder, H. J.; Müllen, K. Molecular characterization of large polycyclic aromatic hydrocarbons in solid petroleum pitch and coal tar pitch by high resolution MALDI ToF MS and insights from ion mobility separation. Carbon 2015, 95, 672680.

(38) Barker, J.; Richards, P.; Snape, C.; Meredith, W. A Novel Technique for Investigating the Nature and Origins of Deposits Formed in High Pressure Fuel Injection Equipment, 2009.

(39) Roussak, O. V.; Gesser, H. D. Applied Chemistry; Springer: Boston, MA, 2013.

(40) Treutler, C. P. O. Industrial use of plasma-deposited coatings for components of automotive fuel injection systems. Surf. Coat. Technol. 2005, 200, 1969-1975.

\section{NOTE ADDED AFTER ASAP PUBLICATION}

Due to a production error, this paper was published on the Web October 29, 2020, with Figure 4 duplicated as Figure 3. The corrected version was reposted on October 30, 2020. 